\title{
Extracellular RNA in Alzheimer's disease
}

\author{
David A. Hicks ${ }^{1,2 *}$ \\ ${ }^{1}$ Division of Neuroscience and Experimental Psychology, School of Biological Sciences, Faculty of Biology, Medicine and Health, University of \\ Manchester, Manchester Academic Health Science Centre, Manchester, UK; ${ }^{2}$ RBMOnline, Bourn Hall, Bourn, Cambridge, UK \\ *Current address: RBMOnline, Bourn Hall, Bourn, Cambridge, UK. \\ Correspondence to: David A. Hicks. RBMOnline, Bourn Hall, Bourn, Cambridge, UK. Email: bmb5dh@gmail.com.
}

\begin{abstract}
Extracellular vesicles (EVs) are released from all cells and represent a heterogeneous mixture of species, differing in size, function, cargo and cellular origin. EVs contain a diverse cargo, including a multitude of, predominantly non-coding, RNA species (exRNA). Alterations in exRNA have been associated with various diseases, including Alzheimer's disease (AD). $\mathrm{AD}$ is a progressive neurodegenerative disease of unknown aetiology which is often associated with diagnosis in the later stages of disease and poor therapeutic options. Given the huge number of people affected by $\mathrm{AD}$, both directly and indirectly, the disease has a significant social and economic burden. Thus, there is a critical need for novel mechanistic and therapeutic avenues of discovery. Hence exRNA "fingerprints" may assist with earlier, more reliable diagnoses and greater insight into disease mechanisms. However, given the large variation in study populations (stage of $\mathrm{AD}$, genetic background) and analysis methods (e.g., biofluids, RNA extraction protocols), there is limited concordance in the published literature. Most studies focus on miRNA alterations, and several independent studies have reported downregulation of miR-125b, miR-29b, miR-342, miR-107, miR-142 and miR-15b in plasma/serum/blood and also miR-29c, miR-127 and miR-139 in CSF. Going forward, as exRNA consortia are assembled, protocols are standardised and novel technologies are leveraged, this field holds great promise for $\mathrm{AD}$ research.
\end{abstract}

Keywords: exRNA; extracellular vesicles (EVs); Alzheimer's disease (AD); biomarkers

Received: 26 August 2020; Accepted: 07 December 2020; Published: 15 May 2021.

doi: $10.21037 /$ exrna-21-2

View this article at: http://dx.doi.org/10.21037/exrna-21-2

\section{Extracellular RNA (exRNA)}

RNA was once thought to have an exclusively intracellular localisation, yet recent discoveries have upended this dogma (1). Various populations of RNA have been discovered in the extracellular milieu, collectively termed exRNA. These RNA subtypes include both protein-coding RNA (mRNA), alongside a multitude of non-coding RNAs, namely microRNAs (miRNA), long noncoding RNAs (lncRNAs), circular RNAs (circRNAs), small nucleolar RNA (snoRNAs), small nuclear RNAs (snRNAs), transfer RNA (tRNAs), ribosomal RNAs (rRNAs) and piwiinteracting RNAs (piRNAs) (2). However, the presence of ribonucleases renders the extracellular environment unfavourable for RNA (3). As such, protection against degradation is afforded in two main ways. Firstly, RNA can be bound in ribonucleoprotein complexes, such as that of Argonaute2 and miRNAs (4). Less frequently RNA can be found as part of lipoprotein complexes (5). Secondly, RNAs can be transported by extracellular vesicles (EVs) (6-8).

\section{EVs}

Comprehensive overviews of $\mathrm{EV}$ biogenesis and release have been recently published (9-11). However, in brief, $\mathrm{EV}$ is an umbrella term encompassing a heterogeneous assortment of vesicular species released from cells (Figure 1). These can be broadly categorised into exosomes and microvesicles (MVs) (10), although some investigators prefer ectosome as an alternative nomenclature for the latter $(9,12)$. The term exosome was originally used to 


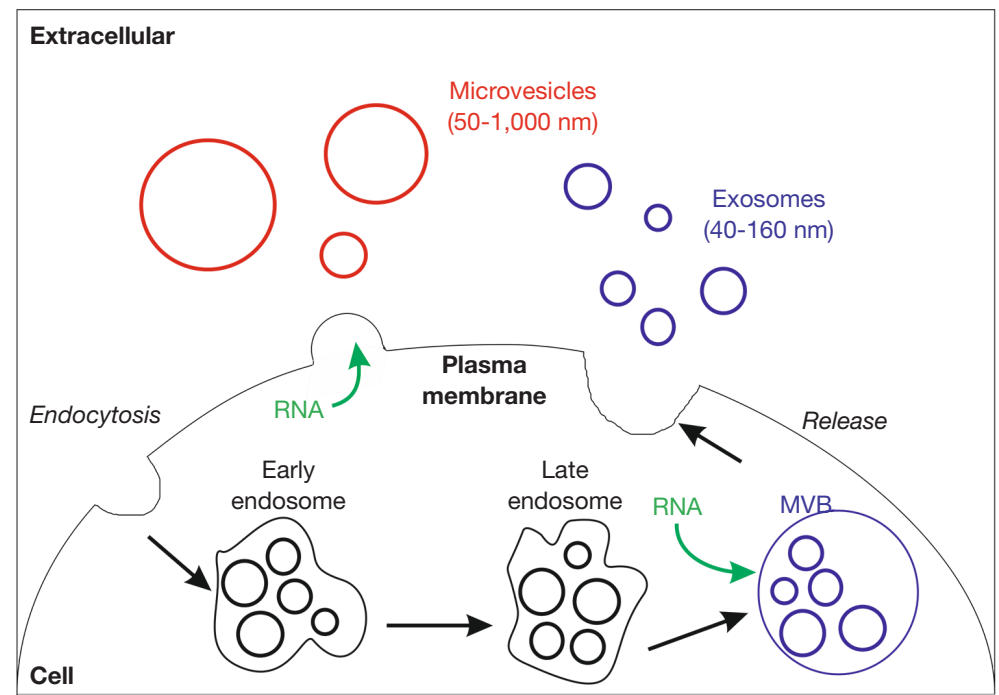

Figure 1 Extracellular vesicles are constitutively released from cells. Endocytosed material progresses from the early to late endosomes, leading to the formation of multi-vesicular bodies (MVBs). RNA can be loaded into these vesicles. Fusion of the MVB with the plasma membrane leads to the release of exosomes into the extracellular milieu. Alternatively, microvesicles, into which RNA can also be loaded, can be released by blebbing directly from the plasma membrane.

describe small vesicles released from reticulocytes (13), with an estimated size of 40-160 nm (9). The possible levels of exosome heterogeneity are well summarised by Kalluri and LeBleu: size, content, function and source (9). Exosomes are derived from intraluminal vesicles contained within endosomal intermediates, multi-vesicular bodies (MVBs), and released from the cell upon MVB fusion with the plasma membrane $(14,15)$. Biogenesis of exosomes can be driven by the ESCRT machinery, acting in a stepwise manner (16-18), although ESCRT-independent exosome release is possible (19). One mechanism for the latter requires ceramide, the generation of which is dependent on neutral type II sphingomyelinase mediating the hydrolysis of sphingomyelin to ceramide (20). Tetraspanins, especially CD63, have also been implicated in ESCRT-independent exosome biogenesis and cargo selection (21). Exosome secretion has been demonstrated in many different cells types and functionally implicated in both physiological and pathological processes $(10,11)$. Although the calculation of exosome release rate is fraught with confounding difficulties, a recent study has estimated a release rate in three breast cell lines. Two breast cancer cell lines (MCF7 and MDA-MB-231) had a release rate of approximately 60-65 exosomes/cell/hour, which was much lower than a comparable non-cancer cell line (MCF10A). In addition to showing the differences in exosome release between cell lines, this study also illuminated the substantial heterogeneity in exosomes species. Exosomes were captured from MCF10A cells by anti-CD63 probes and only 31\% were also immunopositive for CD9, while almost none were immunopositive for CD81. By contrast, in MDA-MB-231 breast cancer cells, almost all exosomes captured by antiCD63 probes were also immunopositive for CD9 and CD81 (22).

MVs are generally much larger, predominantly ranging in size from 50-1,000 $\mathrm{nm}$ (10) and have also been implicated in intercellular communication, most often in cancer cells (23). In contrast to exosomes, MVs are formed by plasma membrane budding and fission, followed by vesicle release into the extracellular milieu (24). MVs are by no means a homogenous population, and incorporate distinct extracellular species such as apoptotic bodies, migrasomes and arrestin-domain-containing protein 1 (ARRDC1)-mediated microvesicles (ARMMs), which have been shown to bud directly from the plasma membrane $(10,25,26)$. Plasma membrane rearrangement is required for MV biogenesis, specifically alterations in protein and lipid composition alongside changes in $\mathrm{Ca}^{2+}$ levels. Enzymatic processes dependent on the latter include scramblases, calpain and aminophospholipid translocases. Altogether, these changes cause physical deformation of the plasma membrane and alterations in actin cytoskeleton structure 
which favour MV formation and release $(10,23,27)$.

Given the overlapping size of exosomes and MVs, in addition to the presence of some common biogenesis factors, sorting machineries and tetraspanins (10), the nomenclature small $\mathrm{EV}$ (sEV) has been encouraged for small vesicles of uncertain origin (28).

\section{Mechanisms of RNA loading}

The mechanisms underpinning specific RNA loading into EVs is not well understood (29). It seems clear that the formation of vesicles results in substantial non-specific incorporation of RNA (30). Incorporation of specific RNAs into EVs likely utilises a range of mechanisms (31). Firstly, miRNAs may be transcriptionally modified to guide their fate. Adenylation of miRNA promoted cellular localisation, whereas 3' end uridylation promoted trafficking of RNA to exosomes (32).

In addition to direct transcript modification, RNA binding proteins (RBPs) have a key role in RNA trafficking to exosomes $(31,33)$. There is a huge number of RNA elements that are recognised by RBPs, as comprehensively reported by phase III of the ENCODE project (34). In another study, using a miRNA bait, isolated RBPs were subjected to proteomic analysis revealing several putative exosomal RNA-bound RBPs. Prominent RBPs identified included major vault protein, HSP90AB, XPO5 and hnRNP family members (33). Another study using exosomes isolated from cultured HEK293 cells found several miRNA which were present in exosomes, but not detectable in cells. Furthermore, the exosomal loading of one of these (miR-223) was dependent on YBX1 (35). Subsequent work identified a more wide-ranging role for YBX1 in defining exosomal RNA composition (36). However, in MDAMB-231 cells, exosome loading of miR-122 was found to be YBX1-independent, but dependent on the Lupus La protein (37). In another study, exosome loading of miR193a was dependent on MVP (38). The binding between RBPs and target miRNAs may be driven by consensus miRNA sequence motifs. The RBP hnRNPA2B1 binds target miRNA through GC-rich tetranucleotide motifs, which drive exosomal loading. Furthermore, this function is dependent on the SUMOylation of hnRNPA2B1 (39). An alternative hexanucleotide miRNA motif was subsequently identified as a binding target of SYNCRIP, an interaction in which SYNCRIP SUMOylation was important (40). Other studies have implicated different RBPs in exosomal miRNA loading, such as GW182 (41), Ago2 (42) and, potentially, connexin $43(43,44)$. Taken together, these findings show that RBPs can drive the loading of specific miRNAs into exosomes. However, different proteins bind to different complements of miRNAs. Despite substantial recent advances, there is still a great deal of uncertainty about the specific mechanisms driving the trafficking of RNA to EVs (29).

Although miRNA motifs have been the focus of the majority of cargo selection research, there is some evidence to support specific trafficking of mRNA to exosomes. A 25 nucleotide "zip code" has been identified in the 3'UTR, which is present in many mRNAs that are trafficked to EVs. The key features of this "zip code" are a CUGCC core presented on a stem loop structure and a binding site for miR-1289. Increased cellular expression of miR-1289 potentiates target mRNA loading in exosomes, suggesting that miRNA can modulate mRNA trafficking to EVs (45).

\section{Alzheimer's disease (AD)}

$\mathrm{AD}$ is a progressive neurodegenerative disease of predominantly unknown aetiology, although approximately $1-2 \%$ of cases are autosomal dominant. It is the most common form of dementia, predominantly affecting those aged over 65 (termed late-onset $\mathrm{AD}$; LOAD) (46). Cases are typically characterised with deficits in learning and memory alongside a range of other symptoms, which may include difficulty with complex attentional tasks, altered behaviour and impairments in language and executive function (47). However, there is a degree of symptomatic variability between individuals (46). Historically, diagnosis has proved very challenging (48), although this has improved markedly with positron emission tomography (PET) and various fluid biomarkers $(46,49,50)$.

The canonical neuropathological hallmarks of $\mathrm{AD}$ are extracellular plaques of the peptide amyloid $\beta(\mathrm{A} \beta)$ and intracellular tau tangles $(46,51)$. $\mathrm{A} \beta$ has been recognised as the main constituent of the $\mathrm{AD}$ hallmark neuritic plaques since the mid-1980s $(52,53)$. A $\beta$ species are formed from amyloidogenic processing of the amyloid precursor protein (APP) (Figure 2). Initially, membrane-bound APP is cleaved by the $\beta$-secretase (BACE1), to generate extracellular sAPP $\beta$ and $\beta$-CTF (aka C99), the latter containing the $\mathrm{A} \beta$ region (54). The $\beta$-CTF is subsequently cleaved by the multiprotein $\gamma$-secretase complex presenilin (PSEN), presenilin enhancer (Pen), anterior pharynx defective (Aph) and nicastrin. Given the multiplicity of PSEN and Aph isoforms, various different $\gamma$-secretase complexes are 


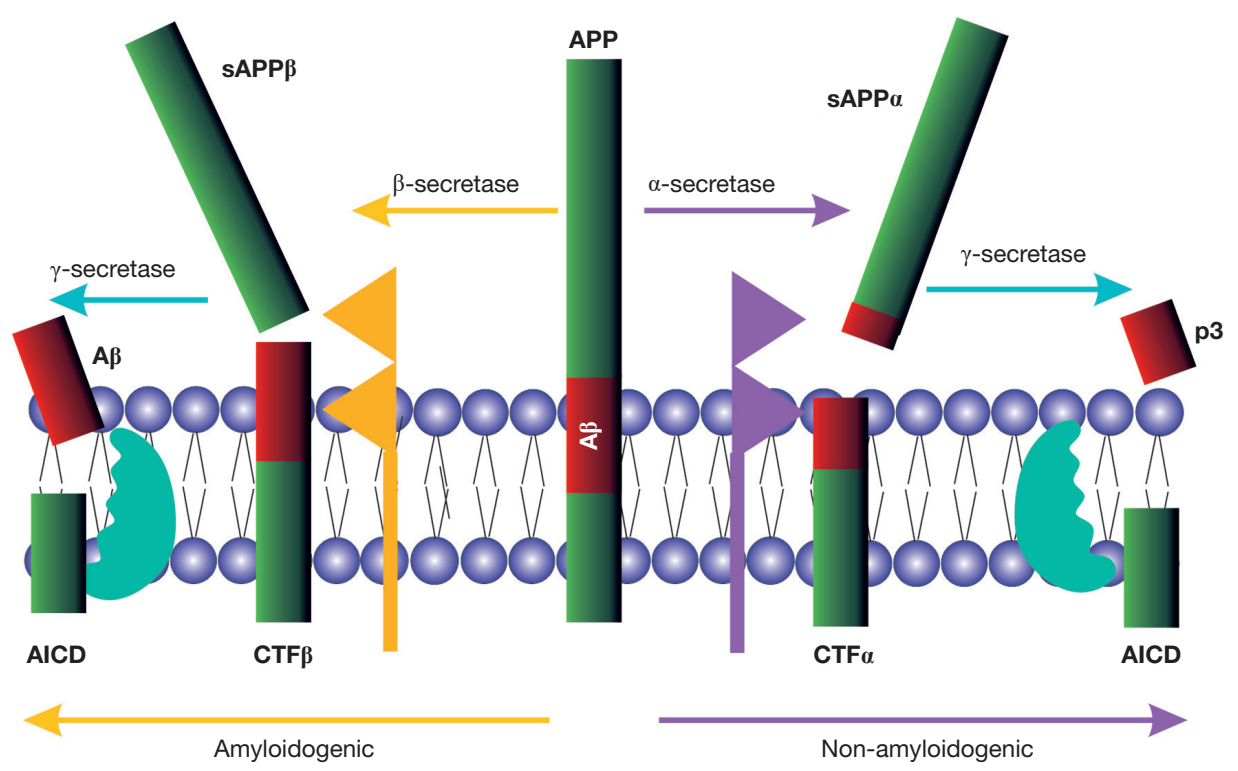

Figure 2 Amyloid precursor protein is processed by amyloidogenic or non-amyloidogenic pathways. The APP holoprotein is sequentially cleaved in either the amyloidogenic or non-amyloidogenic pathways. The former is mediated by the $\beta$-secretase and results in the generation of extracellular sAPP $\beta$ and CTF $\beta$. The latter is then cleaved by the $\gamma$-secretase complex to yield AICD and A $\beta$ species. In the nonamyloidogenic pathway, the $\alpha$-secretase cleaves APP, resulting in the formation of the extracellular sAPP $\alpha$ and CTF $\alpha$. Subsequent $\gamma$-secretase cleavage of CTF $\alpha$ releases AICD and $\mathrm{p} 3$.

possible. The $\gamma$-secretase complex can cleave at various sites in APP, giving rise to several different $\mathrm{A} \beta$ species, predominantly $A \beta_{1-38}, A \beta_{1-40}$ and $A \beta_{1-42}$, the latter being the most aggregation prone $(46,55,56)$. The $\gamma$-secretase cleavage also released the amyloid precursor protein intracellular domain (AICD), which can traffic to the nucleus and act as a transcriptional regulator (57-59). However, APP is predominantly cleaved at the cell surface by a disintegrin and metalloprotease domain-containing protein 10 (ADAM10) (60). This non-amyloidogenic cleavage is within the $A \beta$ region and as such prevents its generation. The $\alpha$-cleavage generates extracellular sAPP $\alpha$ and $\alpha$-CTF (aka C83), followed by $\gamma$-secretase cleavage of $\alpha$-CTF to generate AICD and p3 (56). However, it seems that AICD is only functional when generated in the $\beta$-cleavage pathway (57). Various strands of evidence led to the development of the amyloid cascade hypothesis, which states that $A \beta$ deposition in the brain is the initiating step in $\mathrm{AD}$ pathogenesis (61). Data seem to support a role for $\mathrm{A} \beta$ in $\mathrm{AD}$ (46), but there are also clear inconsistencies in the amyloid hypothesis, especially around the correlation of neuropathological changes with amyloid burden (62-64) and the failure of several amyloid-centric therapies (46). There is a wide-ranging evidentiary basis for the role of hyperphosphorylated, aggregated tau in $\mathrm{AD}$ pathogenesis (46). Unlike $A \beta$, tau pathology shows good correlation with the progress of cognitive dysfunction (62). The physiological role of tau is unclear, but it does function as a microtubule-binding protein (65). The role of tau in $\mathrm{AD}$ is complex and has been reviewed elsewhere $(66,67)$.

\section{MicroRNA (miRNA)}

MiRNA are short (18-25 nt) non-coding RNAs which function in post-transcriptional gene regulation. This is achieved via miRNA binding to target sequences in the 3'UTR of mRNA, usually resulting in down-regulation of mRNA and protein (68). Various studies have investigated alterations in extracellular miRNA levels in $\mathrm{AD}$ (69). There are important differences between cited studies, including the miRNA source (serum, plasma or CSF), purification of $\mathrm{EVs}$ (i.e. different methodologies or no purification), method of RNA isolation and downstream analysis techniques. Interstudy disparities in these parameters can cause significant variation and biases in the resulting data $(70,71)$. In addition, data can be further confounded by sample contamination, such by blood (72) or non-human RNA, predominantly bacterial rRNA (71). Cells have been also shown to release 
more than one exRNA profiles, termed low-density and high-density exRNA. These two sub-populations are enriched in different RNA subtypes (73).

Further studies have predominantly focused on miRNA, identifying changes in many miRNAs. Various recent systematic reviews have summarised the literature in this area. Herrera-Espejo et al. reported 54 studies comparing circulating miRNA between control and late-onset AD. These encompassed various biofluids, including CSF, serum, plasma, blood, monocytes, and lymphocytes. Overall, analysis showed 271 miRNAs with significant expression changes, but none reached the authors' threshold of appearing in four or more independent studies. This was in contrast to brain tissue (i.e. non-circulating miRNA), which revealed 11 miRNA which were significantly altered in four or more independent studies. In addition, the miRNA in different circulating biofluids is often contradictory (74). As published by Nagaraj et al., reducing the threshold to reporting in two or more studies reveals 36 altered miRNA in blood fractions, of which 15 are upregulated, 5 are downregulated and the remainder are discordantly reported. The top six miRNA in terms of the number of independent reports are miR-125b, miR-29-b, miR-342-3p, miR-107, miR-15b and miR-142$3 p$, which are all downregulated, although a recent study has shown miR-15b upregulation (75). However, in CSF, the majority of multiply reported miRNAs are discordant. Those which are concordant are miR-29c, miR-127-3p, miR$139-5 \mathrm{p}$ and miR-9-5p, which appear in 2-3 independent reports (76) (Table 1 and Figure 3).

Further reviews have reiterated the heterogeneity in results and the consequent difficulty in establishing meaningful AD miRNA biomarkers (8,105-108). Reflecting on this challenge, Kosikova et al. report miRNA biomarker panels, comprising anything between two and thirteen different miRNAs. Some of these panels have reached $95 \%$ accuracy in detecting $\mathrm{AD}$ samples. However, the authors and others note the technical difficulties in validating miRNA hits from next generation sequencing, which may lead to the high number of contradictory findings in the literature $(106,109)$. The accuracy of miRNA biomarker panels may be improved by concomitant analysis of the CSF $\mathrm{A} \beta$ : tau ratio (110).

\section{$m i R-125 b$}

Multiple studies have linked extracellular miR-125b with $\mathrm{AD}$ (76), but potential mechanisms by which miR-125b may be involved in $\mathrm{AD}$ are generally not addressed. However, several cell-based studies have investigated putative roles for miR-125b in disease progression. In cultured cells and rat primary neurons, miR-125b induced neuron apoptosis, reduced neurite outgrowth, potentiated inflammation, including induction of prostaglandin-endoperoxide synthase 2 (PTGS2) and cyclin-dependent kinase 5 (cdk5) $(111,112)$. The latter is a known tau kinase (113) and the ability of miR-125b to drive tau phosphorylation (Ser404) via cdk5 was demonstrated (114). In addition, miR-125b is also able to antagonise the tau phosphatases PPP1CA and DUSP6, alongside the anti-apoptotic factor Bcl-W (115). The activity of miR-125b can be antagonised by lncRNA MALAT1 (111). Recent data also suggest that miR-125b is able to block the protective effects on dendritic spines of melatonin 2 (MT2) receptor agonism. In an APP/ PS1 mouse model, a miR-125b sponge reduced dendritic deformations and learning/memory impairments (116). Additional reports have suggested that miR-125b may be induced by reactive oxygen species (ROS) formation (117) or $\mathrm{A} \beta$ (118). A recent study has also linked miR-125b to cortical thickness, glucose metabolism and cognitive performance (119).

However, another study reported miR-125b to be protective in primary cortical neurons via repression of the pro-apoptotic factors BAK and $\mathrm{p} 53$ and that $17 \beta$-estradiol is neuroprotective through induction of $\mathrm{miR}-125 \mathrm{~b}$ expression (120). In line with this, miR-125b reduced $\mathrm{A} \beta$ toxicity in N2a cells and primary mouse neurons by reducing apoptosis and ROS formation, including the suppression of BACE1 expression (121).

\section{$m i R-29 b / m i R-29 c$}

In N2a cells overexpressing $\mathrm{APP}_{695}$, delivery of pre-miR-29b was shown to suppress BACE1 expression by approximately $80 \%$, leading to a reduction in $\mathrm{A} \beta_{1-42}$ of approximately $50 \%$ (122). Levels of miR-29b are suggested to be reduced in $\mathrm{AD}$ and this has been correlated with increased Sp1 mRNA in PBMCs (85). Sp1 has been implicated in a variety of neuroinflammatory processes in neurodegeneration (123). Furthermore, knockdown of miR-29b in mouse brain resulted in ataxia (124).

In an $\mathrm{AD}$ mouse model $\left(\mathrm{APP}_{\mathrm{Sw}} / \mathrm{PS} 1 \Delta \mathrm{E} 9\right)$, miR-29c was increased, although not miR-29a or miR-29b. This was correlated with a decrease in expression of the axonal guidance protein NAV3, which has a miR-29c binding motif in its 3'UTR. The authors thus suggested that NAV3 downregulation may be associated with neurodegeneration (125). In another 
Table 1 Key miRNA identified in multiple studies

\begin{tabular}{|c|c|c|c|c|c|}
\hline $\mathrm{miR}$ & Biofluid & Change & Change (CSF) & References & Role in $A D$ \\
\hline miR-29b & $\begin{array}{l}\text { Plasma/serum/ } \\
\text { blood/PBMC }\end{array}$ & $\begin{array}{l}\text { Downregulated, } \\
\text { but upregulated } \\
\text { in one study ( } 77)\end{array}$ & $\begin{array}{l}<2 \text { independent } \\
\text { reports }\end{array}$ & $(77,83,85-87)$ & $\begin{array}{l}\text { Suppression of BACE1 expression, but also } \\
\text { downregulation of axonal guidance protein NAV3 }\end{array}$ \\
\hline miR-342 & Plasma/serum & Downregulated & $\begin{array}{l}<2 \text { independent } \\
\text { reports }\end{array}$ & $(83,92-94)$ & $\begin{array}{l}\text { Antagonism of miR-342 reduced amyloid burden. } \\
\text { Can downregulate ankyrin G, leading to axonal } \\
\text { dysfunction }\end{array}$ \\
\hline miR-15b & Plasma/serum & $\begin{array}{l}\text { Downregulated, } \\
\text { but upregulated } \\
\text { in one study ( } 77)\end{array}$ & \multicolumn{2}{|c|}{$\begin{array}{l}<2 \text { independent }(75,77,92,94,99,100) \\
\text { reports }\end{array}$} & $\begin{array}{l}\text { Suppressed BACE1 expression and } A \beta \text { generation, } \\
\text { as well as reducing NF- } \mathrm{K} B \text { activity }\end{array}$ \\
\hline miR-142 & Plasma & Downregulated & $\begin{array}{l}<2 \text { independent } \\
\text { reports }\end{array}$ & $(99-101)$ & $\begin{array}{l}\text { Can mitigate the effects of } A \beta \text { on PSD-95 } \\
\text { expression. Also shown to reduce neuropathic pain }\end{array}$ \\
\hline miR-127 & N/A & $\begin{array}{l}<2 \text { independent } \\
\text { reports }\end{array}$ & Downregulated & $(79,102)$ & $\begin{array}{l}\text { Exacerbated OGD-induced cell injury. Inhibits } \\
\text { axonal regeneration after spinal cord transection }\end{array}$ \\
\hline miR-139 & N/A & $\begin{array}{l}<2 \text { independent } \\
\text { reports }\end{array}$ & Downregulated & $(79,102)$ & $\begin{array}{l}\text { Over-expression reduced performance in Morris } \\
\text { water maze, but also shown to reduce cellular } \\
\text { response to pro-inflammatory stimuli }\end{array}$ \\
\hline
\end{tabular}

Key miRNA are listed, i.e., those reported as having altered circulating expression in $\geq 2$ independent studies (76). ${ }^{a}$, in one study (77), miR-125b is only reported as upregulated in exosome-depleted serum.

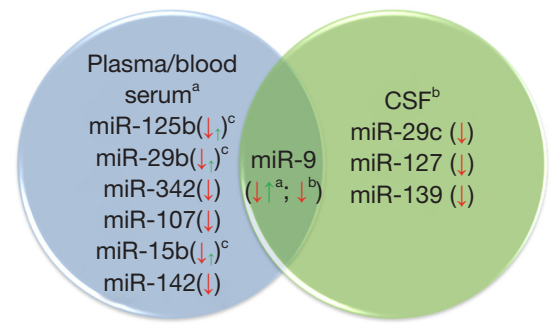

Figure 3 miRNA are altered in biofluids in AD. Several miRNA are altered, concordantly, in several independent studies. This may be either in plasma/serum/blood $\left({ }^{a}\right)$ or $\operatorname{CSF}\left({ }^{b}\right)$. For some miRNA $\left({ }^{c}\right)$, the disparity in arrow size reflects reported downregulation in 4-7 independent studies and upregulation in one study. CSF, cerebrospinal fluid. study, miR-29c was downregulated in AD brain samples. Furthermore, miR-29c suppressed BACE1 expression in SH-SY5Y cells and although A $\beta$ was not measured, there was a decrease in sAPP $\beta$ (126). In blood samples, miR$29 \mathrm{c}$ was found to be negatively correlated with BACE1 expression and further, that miR-29c could promote learning and memory in SAMP8 mice (88). In agreement with this, miR-29c over-expression reduced escape latency in the Morris water maze in $A \beta_{1-40}$-injected rats (78). This rescue of learning and memory in $\mathrm{A} \beta_{1-40}$-injected rats was recapitulated by treatment with miR-29-containing exosomes isolated from cultured cells (127). Yang et al. also demonstrated reduced miR-29c in AD CSF samples and showed miR- 
29c was negatively correlated with DNA methyltransferase 3 (DNMT3), but positively correlated with brain-derived neurotrophic factor (BDNF) (89).

\section{$m i R-342$}

The development of AD has been associated with miR342-3p in post-mortem tissue and 3xTg mouse models. Antagonism of miR-342-3p in transgenic AD mice resulted in improved cognitive performance and reduced hippocampal amyloid burden. Treatment of HT22 cells with suprapathological levels of $A \beta$ increased levels of miR-3423 p via a mechanism dependent on c-jun $\mathrm{N}$-terminal kinase (JNK) (128). In mice expressing the AD-linked Swedish APP mutant $\left(\mathrm{APP}_{\mathrm{Swe}_{\mathrm{w}}}\right), \mathrm{miR}-342-3 \mathrm{p}$ was found be significantly decreased. This resulted in increased expression of chitinase3-like-1 (CHI3L1), leading to endothelial cell inflammation and vascular smooth muscle cell activation (129). In various $\mathrm{PS} 1$ transgenic $\mathrm{AD}$ mouse models, miR-342$5 \mathrm{p}$ was shown to downregulate ankyrin $\mathrm{G}$ expression, occasioning axonal dysfunction in cultured neurons isolated from the transgenic mice. Furthermore, exogenous ankyrin $\mathrm{G}$ addition improved the cognitive performance of 12 month old, but not 18 month old, APP/PS1 mice $(130,131)$.

\section{$m i R-107$}

The miR-15/107 family includes miR-107, but also the AD linked miR-15b (132). Decreases in miR-107 have been shown in AD progression and are particularly associated with the APOE $\varepsilon 4$ allele (133). Analysis of AD patients and $A \beta$-treated neuroblastoma cells has suggested that miR-107 is downregulated in both cases $(134,135)$. Transfection of neuroblastoma cells with miR-107 was able to reverse the deleterious effects of $A \beta$ on cell viability, apoptosis, proliferation and expression of pro-inflammatory cytokines. This may have resulted from miR-107-mediated suppression of the FGFR2/PI3K/Akt pathway (134). These findings are supported by the $\mathrm{A} \beta$-induced increase in SOX21-AS1, a lncRNA, which then acts as a miR107 sponge in SH-SY5Y and SK-N-SH neuroblastoma cells. This downregulation of miR-107 leads to apoptosis and increased tau phosphorylation, which are partially recovered by SOX21-AS1 depletion (136). This paradigm of $A \beta$ induction of lncRNAs and suppression of miR107 was recapitulated for the lncRNA NEAT1 in neuroblastoma cells (137). $A \beta$ is able to exert a multitude of deleterious effects on the vasculature which collectively result in blood- brain barrier (BBB) damage. In a cell model, these changes are reversed by miR-107, via suppression of endophilin-1 expression (138).

In human neuroblastoma and rat pheochromocytoma cells, miR-107 is suppressed by 6-hydroxydopamine treatment, a dopaminergic neurotoxin. Subsequent transfection with miR-107 mimics reduces caspase 3 activation, LDH release and ROS levels, while increasing superoxide dismutase expression, potentially through repression of programmed cell death 10 (PDCD10) (139). The coumarin-derivative osthole can increase miR-107 levels, resulting in suppression of BACE1 expression $(140,141)$ and reduced apoptosis of SH-SY5Y cells and primary neurons in response to APP overexpression. In APP/PS1 transgenic mice, osthole was able, via miR-107, to improve learning and memory alongside decreased A $\beta$ burden (140). However, miR-107 may also suppress the $\alpha$-secretase, ADAM10 (142). miR-107 has been shown to regulate the $\mathrm{cdk} 5 / \mathrm{p} 35$ complex, which is able to phosphorylate tau. This suggests that miR-107 dysfunction may lead to increased tau phosphorylation via increases cdk5/p35 activity (143).

In transgenic mice, miR-107 has also been reported to suppress NF- $\mathrm{KB}$ and SYK, leading to improvement in spatial memory and reduced apoptosis (144). In the transgenic Tg19959 mice, cofilin expression is increased and miR-107 is reduced, the former being a major constituent of the Hirano bodies seen in AD brains. Restoration of miR-107 levels suppresses the translation of cofilin and reduces the abundance of neuronal cofilin rod-like inclusions (145). In wild type C57 mice, injection of $A \beta_{1-42}$ aggregates led to spatial memory dysfunction, impaired long term potentiation (LTP) and loss of pyramidal neurons in the CA1 region of the hippocampus. These changes were underpinned by suppression of BDNF expression and TrkB signalling. Collectively, these pathological changes were reversed by the administration of miR-107 mimics (146).

\section{$m i R-15 b$}

Although miR-15b is in the same family as miR-107 (132), far fewer mechanistic studies have been published. However, miR-15b was found to be significantly reduced in sporadic AD brain compared to control. This was associated with an increase in BACE1 mRNA and protein. In SH-SY5Y cells, miR-15b was able to decrease BACE1 expression via binding the BACE1 3'UTR. However, the overall picture is complicated by the protective potential of 
anti-miR-15b transfection against A $\beta$ toxicity in SH-SY5Y cells (147). A subsequent study also showed binding of miR-15b to the BACE1 3'UTR and repression of BACE1 expression in SH-SY5Y cells. In these cells, $\mathrm{Li}$ and Wang also showed miR-15b transfection to reduce sAPP $\beta, A \beta_{1-40}$ and $A \beta_{1-42}$ alongside a concomitant increase in SAPP $\alpha$. In addition, a miR-15b mimic was shown to bind the $N F-\kappa B 1$ 3'UTR and reduce its expression from a reporter construct. This targeting of NF- $\mathrm{\kappa B}$ signalling was associated with suppression of $\mathrm{APP}_{\text {Swe }}$-induced increases in TNF $\alpha, \mathrm{IL}-1 \beta$, IL-6 and PGE2 expression (148). In HEK293 cells, curcumin has been suggested to increase miR-15b levels, which consequently suppresses APP expression and A $\beta$ levels (149).

\section{$m i R-142$}

In two independent human sample sets and a mouse $\mathrm{AD}$ model (APP/PSEN1 $\triangle \mathrm{E} 9)$, miR-142 was downregulated. Furthermore, in SH-SY5Y cells, $A \beta_{1-42}$ treatment caused reduced PSD-95 expression, but this effect was mitigated by miR-142 transfection. No miR-142 binding motif was discerned in the PSD-95, so it is possible miR-142 modulates expression of a PSD-95 binding partner rather than PSD95 itself (150). In a rat model, miR-142 was shown to reduce neuropathic pain via targeting of soluble guanylate cyclase. The authors suggested this may have relevance for people with $\mathrm{AD}$ who suffer from neuropathic pain (151). Conversely, Zhang et al. showed A $\beta$ could upregulate miR142 in human neuronal cells resulting in neurotoxicity, which was suppressed by circHDAC9 expression (152). In addition to its implication in several biomarker and cellular studies, a polymorphism in miR-142 has been associated with a reduced risk of $\mathrm{AD}$. A particular variant (rs2526377:A>G) affects the promoter activity of miR-142 and reduces its expression. The study suggests that this may lead to depression of genes such as PICALM and TGFBR1, which could be beneficial in $\mathrm{AD}$ (153). Interestingly, miR142 was also the target of a novel nanobiosensor, which couples SYBR Green fluorescence with graphene oxide quenching to sensitively detect miRNA in body fluids (154).

\section{$m i R-127$}

No mechanistic studies are available in the published literature linking miR-127 to AD. However, overexpression of miR-127 did exacerbate cell injury induced by oxygen-glucose deprivation (OGD) in PC12 cells (155).
Similarly, after spinal cord transection, miR-127 increased neuronal loss and cell apoptosis, while inhibiting axonal regeneration (156).

\section{miR-139}

There is only a single report exploring the possible mechanistic effects of miR-139 in AD. This study, by Tang et al., shows increased APP and miR-139 expression in the accelerated aging SAMP8 mouse model. Over-expression of miR-139 in SAMP8 mice significantly reduces performance in the Morris water maze. However, miR-139 also suppresses cannabinoid CB2 expression, which is linked to microglial activation and miR-139 also reduced the response of cultured neurons to pro-inflammatory stimuli (157).

\section{$\operatorname{miR}-9$}

A novel technology using two-photon fluorescent carbon dots showed miR-9 to be upregulated in early onset $\mathrm{AD}$, but reduced in late onset AD (158). Chronic cerebral hypoperfusion has been shown to be symptom of $\mathrm{AD}$ and this caused increased miR-9 in a rat model. Treatment with miR-9 antagonists reduced memory impairment, dendritic spine loss and inhibition of long-term potentiation (159). In murine neural stem cells and human neuroblastoma cells, zoanthamine and osthole were suggested to be protective against APP-induced apoptosis, in a miR-9dependent process (160-162). Treatment of primary hippocampal neurons with $\mathrm{A} \beta_{1-42}$ oligomers resulted in miR-9 downregulation and activation of the CAMKK2AMPK pathway, leading to dendritic spine loss and tau phosphorylation (Ser262). Over-expression of miR-9 led to reduced CAMKK2 expression, dendritic spine loss and tau phosphorylation (163). In HeLa cells, luciferase reporter constructs were used to demonstrate the ability of miR-9 to repress TGFBI, TRIM2, SIRT1 genes and in the case of the latter, co-transfection with miR-181c had an additive effect. The authors speculated that downregulation of miR-9 in $\mathrm{AD}$ may be a protective mechanism, to, for example, increase SIRT1 expression (164).

\section{Piwi-interacting RNA (piRNA)}

First described in 2006, piRNA are 26-30 nt in length, with 2'-O-methylation at their 3' end and can promote gene silencing via interactions with Piwi proteins. Piwi proteins and piRNA can directly modify chromatin 
structure and nuclear histone proteins. This is done through interaction with DNA methyltransferase (DNMT), which can methylate promoter regions, suppressing transcription (165).

In disease, alterations in piRNA have been overwhelmingly linked to cancer (165), although there are also some reported cellular alterations in $\mathrm{AD}(166)$ as well SNPs in piRNA-associated pathway genes (167). In order to improve accuracy of the extracellular miRNA signature in $\mathrm{AD}$, piRNA have been used. An CSF AD signature was developed, comprising three miRNA (miR-27a-3p, miR30a-5p and miR-34c-3p) and three piRNA (piR_019324, piR_019949, piR_020364). The accuracy can be further improved by concomitant CSF analysis of $\mathrm{A} \beta_{1-42}$, tau and phospho-tau (168), in line with the findings of others (110).

\section{Long non-coding RNA (IncRNA)}

LncRNAs comprise a class of non-coding RNAs that are in excess of $200 \mathrm{nt}$ and account for a major part of the non-coding transcriptome (169). Although lncRNAs are dysregulated in AD brains (169), there has been limited evidence of this in circulating biofluids (170). An early study reported changes in lncRNA (RP11-462G22.1 and PCA3) between $\mathrm{AD}$ and healthy control samples although it is of note that neither IncRNA was discriminatory of $\mathrm{AD}$ from Parkinson's disease (PD) (90). However, these findings have not been subsequently validated and the majority of subsequent work in this field has focused on miRNA. Yet there have been some very recent reports focusing on lncRNAs, focusing on BACE1. Comparing control and AD plasma samples, BACE1-AS was significantly reduced in AD plasma. There was no reported change in other lncRNAs, specifically lnc 51A, lnc 17A and BC200 (171). However, another study showed a significant reduction of plasma BACE1-AS only in pre-AD samples relative to control, but a significantly increase in full $\mathrm{AD}$ samples. However, when exosomes were isolated, there was no significant change in BACE1-AS levels in AD (172). Targeting of BACE1-AS by siRNA increased in vitro proliferation of hippocampal neurons, as improving learning and memory in accelerated aging SAMP8 mice (173). Application of exogenous $A \beta_{1-42}$ to either SH-SY5Y cells or C57/BL6J mice caused an increase in BACE1-AS, BACE1 mRNA and BACE1 protein, alongside increased $A \beta_{1-40}$, all of which was mitigated by BACE1-AS siRNA (174).

\section{Circular RNA (circRNA)}

Exonic circular RNAs (circRNAs) represent a substantial class of regulatory non-coding endogenous RNAs. These are mostly expressed from protein-coding genes, comprising single or multiple exons. They are generated by backsplicing, which happens in a reversed orientation as compared with canonical splicing (175). CircRNAs have been a recent focus of exRNA investigation. Using microarrays on peripheral blood mononuclear cells (PBMCs) from control and $\mathrm{AD}$ donors, Li et al. identified 4,060 differentially expressed circRNAs (1,990 upregulated and 2,070 downregulated). Overall, gene ontology analysis of these data identified MAPK, mTOR, AMPK, and WNT as key signalling pathways. Eight circRNAs were selected for qPCR validation and this confirmed the upregulation of circRNA_000843, circRNA_101618 and circRNA_405619 (176).

CircHDAC9 was shown to be downregulated in serum of patients with MCI or AD, as compared to control. A mechanistic model was suggested, whereby this downregulation is induced by $\mathrm{A} \beta$ species and decreased circHDAC9 leads to increased miR-138 and consequently SIRT1 and ADAM10 protein, which reduces nonamyloidogenic processing of APP, leading to increased $\mathrm{A} \beta$ (177). The ability of $\mathrm{A} \beta$ to suppress circHDAC9 has been corroborated by a recent study which linked this to increases in miR-142-5p. The effects of $A \beta$ on circHDAC9 and miR-142-5p were shown to be reversed by berberine (152), a plant alkaloid (178) which has been suggested as a possible therapeutic in $\mathrm{AD}(179)$.

\section{mRNA}

The role of extracellular mRNA is unclear, although some functional effects have been suggested (30). Few studies have assessed altered extracellular mRNA profiles between control and $\mathrm{AD}$ samples, but Gui et al. identified seven altered mRNAs (APP, $\alpha$-synuclein, tau, NF-L, DJ-1/PARK7, fractalkine, and neurosin). Of the mRNAs identified, only tau was altered in AD (a significant decrease), but not Parkinson's disease (90). APP mRNA was also identified as being enriched in $\mathrm{AD}$ by a recent study, but this did not reach statistical significance (180). This study by Yan $e t a l$. identified presymptomatic increases in phosphoglycerate dehydrogenase (PHGDH) extracellular mRNA with progression to AD. PHGDH serum exRNA and brain protein expression increases in $\mathrm{AD}$ were validated 
by using five additional published cohorts. Mechanistically, the authors tentatively suggest that, as PHGDH catalyzes serine biosynthesis in the brain, which is required for glycine production, there may be a link to excitotoxicity (180). Furthermore, in another report, mRNA for IL-6, IL12 , and TNF $\alpha$ were all elevated in exosomes secreted by macrophages following treatment with $\mathrm{A} \beta$. Interestingly, the response was significantly enhanced in macrophages isolated from aged patients ( $>65$ years) (181).

Modification of the actual mRNA may result in altered trafficking to $\mathrm{EVs}$ in $\mathrm{AD}$, as this can be influenced by 3 ' end modification (32). In $\mathrm{AD}$, there are examples of alternative polyadenylation (APA), such as increased neocortical expression of a long COX-2 isoform in $\mathrm{AD}$. In this case, the alternative polyadenylation generates a more unstable transcript which is rapidly degraded (182). Subsequent transcriptomic analyses have revealed widespread APA alterations in $\mathrm{AD}$ brains (183) and that 3' poly(A) regions can be lengthened or shortened in $\mathrm{AD}$, depending on the transcript (184). Such changes in APA can be responsive to cellular stress, as arsenite treatment caused a global reduction in poly(A) tail length (185). This treatment can also cause aggregation of RBPs, such as TDP-43 (186).

\section{RNA-binding proteins in AD}

It is unclear exactly why exRNA profiles are altered in $\mathrm{AD}$, but one potential route is through RBP dysfunction, such that RNA trafficking to EVs is dysregulated. One example of this is the AD association of SNPs in TARBP2 (95), which encodes a protein component of the RISCloading complex alongside Dicer and Argonaute 2 (187). In addition to SNPs which may affect function of the translated protein, RBPs are often incorporated into cellular inclusions in neurodegeneration. Examples of this in AD include TDP-43 (188) and RBM45 (189) and in both cases inclusion formation can be driven by a variety of cell stresses $(189,190)$. Recent work has suggested that, along with TDP-43, the RBPs FUS and matrin 3 are present in cytoplasmic inclusions in AD patients and pR5 (tau P301L) mice (191). The putative RBP, connexin 43, and also several hnRNP family members have also been strongly linked with $\operatorname{AD}(44,192,193)$.

In iPSC-derived human neurons, $24 \mathrm{~h}$ treatment with $1 \mu \mathrm{M}$ oligomeric $\mathrm{A} \beta_{1-42}$ resulted in several proteomic changes germane to exRNA. In AF22 cells (wild type $\mathrm{APP}), \mathrm{hnRNPF}$ was reduced by $50 \%$ on $\mathrm{A} \beta_{1-42}$ challenge, alongside significant reductions in expression of Musashi homolog 2 and TDP-43, which are all RBPs. None of these changes were significant in the ADP2 neurons, which harbour a V717I mutation in APP (194). Furthermore, YBOX1 phosphorylation is increased by $\mathrm{A} \beta_{1-42}$ (194), which may have significant effects on its ability to traffic RNA to EVs (195). In AD entorhinal cortices, there is evidence of global aberrant splicing, alongside selective reduction in the levels of hnRNP A/B proteins (196). In addition, Sackmann and Hallbeck also identified $\mathrm{A} \beta_{1-42}$-induced alterations in expression of proteins linked to vesicular trafficking and fusion (194).

Taken together, these data suggest a multitude of potential mechanisms for the dysregulation of RNA trafficking to EVs in AD. These include (I) altered APA; (II) SNPs in genes in RNA trafficking/processing machinery; (III) sequestration of RBPs in cellular inclusions; (IV) stressinduced downregulation of RBP expression; (V) altered posttranslational modification (e.g., phosphorylation) of RBPs and (VI) dysfunctional vesicular trafficking and fusion. These possible processes are concomitant with large scale alterations in the cellular expression profiles of RNA subtypes, but especially mRNA and miRNA (68).

\section{exRNA stoichiometry and cell entry}

It has previously been suggested that most EVs do not carry biologically significant numbers of miRNA, specifically that approximately $100 \mathrm{EVs}$ would be required to isolate one miRNA (197). This was corroborated using a novel methodology in cell culture supernatant, focusing on miR-21 and miR-221 (198). These findings conflict with data from neural stem cell cultures, where at least 10 copies of miR-1246 were found per EV (199). However, as highlighted by O'Brien et al., such attempts at stoichiometric analysis face considerable technical confounders $(29,200)$. However, the potentially low numbers of miRNA per vesicle may be offset by the number of vesicles released by an individual cell. Although the rate of $\mathrm{EV}$ release is likely highly variable between cells and dependent on conditions, HUVECs were shown to release 37 vesicles per cell under basal conditions (201). Additionally, in a disease like $\mathrm{AD}$, the disease course is so long that exRNA could exert various functions for decades.

The study of Stevanato et al. represents one approach to assessing the functionality of exRNA (199), but many others have been deployed. Although there is some discrepancy in the field, the assembled data generally favours the notion 
that EV RNA cargo is functional $(29,202)$.

\section{Conclusions}

RNA can be isolated from the extracellular milieu. It is predominantly non-coding (chiefly miRNA) and encapsulated in EVs. In AD, many attempts have been made to identify exRNA biomarker signatures that may be used as a diagnostic tool. These approaches vary from single miRNA biomarkers, to miRNA panels, lncRNAs, circRNAs and combinations of exRNA signatures with $\mathrm{A} \beta$ and phospho-tau data. Mechanistically, several of the exRNA species identified have been explored in vitro to develop understanding of the putative effects of exRNA on recipient cells. Understanding of the role of exRNA in $\mathrm{AD}$ is advancing apace, but this field, more than most, also brings with it a wide range of technical considerations with the potential to confound results.

\section{Future perspectives}

Research on exRNA has focused on two overlapping, but also distinct, areas: specifically biomarkers and in vitro mechanistic studies. It is likely the former that will bring more rapid benefits. This is due to the availability of samples from individuals living with $\mathrm{AD}$ and the observational nature of these studies, that is to say an understanding of exRNA function is not intrinsically required to develop an $\mathrm{AD}$ exRNA "fingerprint". The principle, as outlined in dozens of research publications, is quite straightforward: biofluid isolation from large populations, followed by RNA sequencing and "fingerprint" development. However, the huge disparity in results shows clearly that simplicity of principle does not equate to simplicity of practice. Every stage of the process offers the potential to diverge from the protocols of others. Different studies display differences in MMSE score of study participants, biofluid, isolation of EVs (many studies don't specifically isolate EVs) and RNA extraction technique, inter alia $(76,203)$. Given these technical issues, elegantly detailed by O'Brien et al. (29), it should come as no surprise that exRNA studies in $\mathrm{AD}$ rarely provide concordant results (74). This also highlights the importance of arriving at a consensus in the EV field and, as such, standard protocols (i.e., MISEV guidelines) are vital (28). It seems clear that exRNA biomarker studies will only bring benefit with standardised protocols across multiple centres. In practice, this requires a consortium, given the lack of incentive for individual investigators to repeat and validate the work of others. Thus the exRNA Atlas is a hugely positive development, a NIH-funded consortium of experts comprehensively assessing exRNA (204).

Independently of the technical difficulties of EV, $\mathrm{AD}$ research presents a slew of challenges. Foremost among these is the challenge of diagnosing $\mathrm{AD}$, in the frequent absence of neuroimaging or biomarker assays. Further complicating this is the frequent coexistence of $\mathrm{AD}$ with other pathologies, including Lewy bodies and/or TDP43 inclusions $(188,205)$. These differences in pathology are accompanied by vast genetic differences (206). Taken together, these findings are highly suggestive of substantial pathological, biochemical and genetic heterogeneity in study populations with an $\mathrm{AD}$ diagnosis. This heterogeneity may confound efforts to reliably discover alternations in exRNA profiles associated with $\mathrm{AD}$. As has been previously reported (76,203), as indicated by MMSE scores, some exRNA studies have a predominantly mild cognitive impairment (MCI, pre-AD) cohort, while other studies focus on late-AD cohorts.

The second focus of exRNA in $\mathrm{AD}$ is in vitro mechanistic studies. Certainly, published studies have shown that miRNA are capable of modulating, for example, BACE1, $\mathrm{NF}-\kappa \mathrm{B}$ and learning/memory. The difficulty is finding an appropriate model system for assessing the relevance of these in vitro findings for $\mathrm{AD}$ in human patients. There is a multiplicity of unanswered questions, including how the exRNA profile changes through the $\mathrm{AD}$ disease course, the extent to which the exRNA can enter recipient cells in vivo over time (decades in $\mathrm{AD}$ ) and whether transferred exRNA actually does have an effect on the translational programme. Transfection of cultured cells with high concentrations of a particular miR over a $24-48$-hour time period, while not without its uses, is quite far removed from the physiology of an individual with AD. However, the rapid advance of analytical technologies may result in answers to these key questions. Substantial progress has been made on analysis of single EVs (207-212) and single cell transcriptomics (213), alongside the emergence of single cell proteome analytic techniques (214). Taken together, a nexus of these novel technologies may offer the ability to analyse the exRNA content of single $\mathrm{EV}$ s from individuals with $\mathrm{AD}$ throughout the disease course. This could be combined with single cell transcriptomic and proteomic analysis of recipient cells, in vivo, to understand the extent to which exRNA can exert functional effects.

Overall, the studies of exRNA in AD to date have 
demonstrated both the potential and limitations of this field. The approach to date, predominantly consisting of individual investigators (or small groups) assessing single cohorts, has served its purpose in demonstrating the potential of exRNA biomarkers. Going forward, a new approach is imperative, developing large consortia (204), standardising protocols (28) and leveraging emerging technologies $(210,213,214)$. This may then help realise the immense promise that this field holds.

\section{Acknowledgments}

Funding: None.

\section{Footnote}

Conflicts of Interest: The author has completed the ICMJE uniform disclosure form (available at http://dx.doi. org/10.21037/exrna-21-2). The author has no conflicts of interest to declare.

Ethical Statement: The author is accountable for all aspects of the work in ensuring that questions related to the accuracy or integrity of any part of the work are appropriately investigated and resolved.

Open Access Statement: This is an Open Access article distributed in accordance with the Creative Commons Attribution-NonCommercial-NoDerivs 4.0 International License (CC BY-NC-ND 4.0), which permits the noncommercial replication and distribution of the article with the strict proviso that no changes or edits are made and the original work is properly cited (including links to both the formal publication through the relevant DOI and the license). See: https://creativecommons.org/licenses/by-nc-nd/4.0/.

\section{References}

1. Brody H. Extracellular RNA. Nature 2020;579:S1 .

2. Kim KM, Abdelmohsen K, Mustapic M, et al. RNA in extracellular vesicles. Wiley Interdiscip Rev RNA 2017;8:10.1002/wrna.1413.

3. Sorrentino S. Human extracellular ribonucleases: multiplicity, molecular diversity and catalytic properties of the major RNase types. Cell Mol Life Sci 1998;54:785-94.

4. Arroyo JD, Chevillet JR, Kroh EM, et al. Argonaute2 complexes carry a population of circulating microRNAs independent of vesicles in human plasma. Proc Natl Acad
Sci U S A 2011;108:5003-8.

5. Vickers KC, Palmisano BT, Shoucri BM, et al. MicroRNAs are transported in plasma and delivered to recipient cells by high-density lipoproteins. Nat Cell Biol 2011;13:423-33.

6. Lotvall J, Valadi H. Cell to cell signalling via exosomes through esRNA. Cell Adh Migr 2007;1:156-8.

7. Valadi H, Ekstrom K, Bossios A, et al. Exosome-mediated transfer of mRNAs and microRNAs is a novel mechanism of genetic exchange between cells. Nat Cell Biol 2007;9:654-9.

8. Momen-Heravi F, Getting SJ, Moschos SA. Extracellular vesicles and their nucleic acids for biomarker discovery. Pharmacol Ther 2018;192:170-87.

9. Kalluri R, LeBleu VS. The biology, function, and biomedical applications of exosomes. Science 2020;367:eaau6977.

10. van Niel G, D'Angelo G, Raposo G. Shedding light on the cell biology of extracellular vesicles. Nat Rev Mol Cell Biol 2018;19:213-28.

11. Colombo M, Raposo G, Théry C. Biogenesis, secretion, and intercellular interactions of exosomes and other extracellular vesicles. Annu Rev Cell Dev Biol 2014;30:255-89.

12. Cocucci E, Meldolesi J. Ectosomes. Curr Biol 2011;21:R940-1. Erratum in: Curr Biol 2012;22:1359.

13. Johnstone RM, Adam M, Hammond JR, et al. Vesicle formation during reticulocyte maturation. Association of plasma membrane activities with released vesicles (exosomes). J Biol Chem 1987;262:9412-20.

14. Pan BT, Teng K, Wu C, et al. Electron microscopic evidence for externalization of the transferrin receptor in vesicular form in sheep reticulocytes. J Cell Biol 1985;101:942-8.

15. Harding C, Heuser J, Stahl P. Endocytosis and intracellular processing of transferrin and colloidal gold-transferrin in rat reticulocytes: demonstration of a pathway for receptor shedding. Eur J Cell Biol 1984;35:256-63.

16. Tamai K, Tanaka N, Nakano T, et al. Exosome secretion of dendritic cells is regulated by Hrs, an ESCRT- 0 protein. Biochem Biophys Res Commun 2010;399:384-90.

17. Colombo M, Moita C, van Niel G, et al. Analysis of ESCRT functions in exosome biogenesis, composition and secretion highlights the heterogeneity of extracellular vesicles. J Cell Sci 2013;126:5553-65.

18. Hurley JH. ESCRT complexes and the biogenesis of multivesicular bodies. Curr Opin Cell Biol 2008;20:4-11.

19. Stuffers S, Sem Wegner C, Stenmark H, et al. 
Multivesicular endosome biogenesis in the absence of ESCRTs. Traffic 2009;10:925-37.

20. Trajkovic K, Hsu C, Chiantia S, et al. Ceramide triggers budding of exosome vesicles into multivesicular endosomes. Science 2008;319:1244-7.

21. van Niel G, Charrin S, Simoes S, et al. The tetraspanin CD63 regulates ESCRT-independent and -dependent endosomal sorting during melanogenesis. Dev Cell 2011;21:708-21.

22. Chiu YJ, Cai W, Shih YR, et al. A Single-Cell Assay for Time Lapse Studies of Exosome Secretion and Cell Behaviors. Small 2016;12:3658-66.

23. Al-Nedawi K, Meehan B, Micallef J, et al. Intercellular transfer of the oncogenic receptor EGFRvIII by microvesicles derived from tumour cells. Nat Cell Biol 2008;10:619-24.

24. Tricarico C, Clancy J, D'Souza-Schorey C. Biology and biogenesis of shed microvesicles. Small GTPases 2017;8:220-32.

25. Ma L, Li Y, Peng J, et al. Discovery of the migrasome, an organelle mediating release of cytoplasmic contents during cell migration. Cell Res 2015;25:24-38.

26. Nabhan JF, Hu R, Oh RS, et al. Formation and release of arrestin domain-containing protein 1-mediated microvesicles (ARMMs) at plasma membrane by recruitment of TSG101 protein. Proc Natl Acad Sci U S A 2012;109:4146-51.

27. Piccin A, Murphy WG, Smith OP. Circulating microparticles: pathophysiology and clinical implications. Blood Rev 2007;21:157-71.

28. Théry C, Witwer KW, Aikawa E, et al. Minimal information for studies of extracellular vesicles 2018 (MISEV2018): a position statement of the International Society for Extracellular Vesicles and update of the MISEV2014 guidelines. J Extracell Vesicles 2018;7:1535750.

29. O'Brien K, Breyne K, Ughetto S, et al. RNA delivery by extracellular vesicles in mammalian cells and its applications. Nat Rev Mol Cell Biol 2020;21:585-606.

30. Hicks DA, Jones AC, Corbett NJ, et al. Extracellular Vesicles Isolated from Human Induced Pluripotent Stem Cell-Derived Neurons Contain a Transcriptional Network. Neurochem Res 2020;45:1711-28.

31. Abels ER, Breakefield XO. Introduction to Extracellular Vesicles: Biogenesis, RNA Cargo Selection, Content, Release, and Uptake. Cell Mol Neurobiol 2016;36:301-12.

32. Koppers-Lalic D, Hackenberg M, Bijnsdorp IV, et al. Nontemplated nucleotide additions distinguish the small
RNA composition in cells from exosomes. Cell Rep 2014;8:1649-58.

33. Statello L, Maugeri M, Garre E, et al. Identification of RNA-binding proteins in exosomes capable of interacting with different types of RNA: RBP-facilitated transport of RNAs into exosomes. PLoS One 2018;13:e0195969.

34. Van Nostrand EL, Freese P, Pratt GA, et al. A largescale binding and functional map of human RNA-binding proteins. Nature 2020;583:711-9.

35. Shurtleff MJ, Temoche-Diaz MM, Karfilis KV, et al. Y-box protein 1 is required to sort microRNAs into exosomes in cells and in a cell-free reaction. Elife 2016;5:e19276.

36. Shurtleff MJ, Yao J, Qin Y, et al. Broad role for YBX1 in defining the small noncoding RNA composition of exosomes. Proc Natl Acad Sci U S A 2017;114:E8987-E8995.

37. Temoche-Diaz MM, Shurtleff MJ, Nottingham RM, et al. Distinct mechanisms of microRNA sorting into cancer cell-derived extracellular vesicle subtypes. Elife 2019;8:e47544.

38. Teng Y, Ren Y, Hu X, et al. MVP-mediated exosomal sorting of miR-193a promotes colon cancer progression. Nat Commun 2017;8:14448.

39. Villarroya-Beltri C, Gutiérrez-Vázquez C, Sánchez-Cabo F, et al. Sumoylated hnRNPA2B1 controls the sorting of miRNAs into exosomes through binding to specific motifs. Nat Commun 2013;4:2980.

40. Santangelo L, Giurato G, Cicchini C, et al. The RNABinding Protein SYNCRIP Is a Component of the Hepatocyte Exosomal Machinery Controlling MicroRNA Sorting. Cell Rep 2016;17:799-808.

41. Gibbings DJ, Ciaudo C, Erhardt M, et al. Multivesicular bodies associate with components of miRNA effector complexes and modulate miRNA activity. Nat Cell Biol 2009;11:1143-9.

42. McKenzie AJ, Hoshino D, Hong NH, et al. KRAS-MEK Signaling Controls Ago2 Sorting into Exosomes. Cell Rep 2016;15:978-87.

43. Soares AR, Martins-Marques T, Ribeiro-Rodrigues $\mathrm{T}$, et al. Gap junctional protein $\mathrm{Cx} 43$ is involved in the communication between extracellular vesicles and mammalian cells. Sci Rep 2015;5:13243.

44. Varela-Eirin M, Varela-Vazquez A, Rodríguez-Candela Mateos M, et al. Recruitment of RNA molecules by connexin RNA-binding motifs: Implication in RNA and DNA transport through microvesicles and exosomes. Biochim Biophys Acta Mol Cell Res 2017;1864:728-36. 45. Bolukbasi MF, Mizrak A, Ozdener GB, et al. miR- 
1289 and "Zipcode"-like Sequence Enrich mRNAs in Microvesicles. Mol Ther Nucleic Acids 2012;1:e10.

46. Long JM, Holtzman DM. Alzheimer Disease: An Update on Pathobiology and Treatment Strategies. Cell 2019;179:312-39.

47. McKhann GM, Knopman DS, Chertkow H, et al. The diagnosis of dementia due to Alzheimer's disease: recommendations from the National Institute on AgingAlzheimer's Association workgroups on diagnostic guidelines for Alzheimer's disease. Alzheimers Dement 2011;7:263-9.

48. Bondi MW, Edmonds EC, Salmon DP. Alzheimer's Disease: Past, Present, and Future. J Int Neuropsychol Soc 2017;23:818-31.

49. Yang T, O'Malley TT, Kanmert D, et al. A highly sensitive novel immunoassay specifically detects low levels of soluble Abeta oligomers in human cerebrospinal fluid. Alzheimers Res Ther 2015;7:14.

50. Zetterberg H, Burnham SC. Blood-based molecular biomarkers for Alzheimer's disease. Mol Brain 2019;12:26.

51. Masters CL, Bateman R, Blennow K, et al. Alzheimer's disease. Nat Rev Dis Primers 2015;1:15056.

52. Glenner GG, Wong CW. Alzheimer's disease: initial report of the purification and characterization of a novel cerebrovascular amyloid protein. Biochem Biophys Res Commun 1984;120:885-90.

53. Masters CL, Simms G, Weinman NA, et al. Amyloid plaque core protein in Alzheimer disease and Down syndrome. Proc Natl Acad Sci U S A 1985;82:4245-9.

54. Vassar R, Bennett BD, Babu-Khan S, et al. Beta-secretase cleavage of Alzheimer's amyloid precursor protein by the transmembrane aspartic protease BACE. Science 1999;286:735-41.

55. Voytyuk I, De Strooper B, Chávez-Gutiérrez L. Modulation of $\gamma$ - and $\beta$-Secretases as Early Prevention Against Alzheimer's Disease. Biol Psychiatry 2018;83:320-7.

56. Andrew RJ, Kellett KA, Thinakaran G, et al. A Greek Tragedy: The Growing Complexity of Alzheimer Amyloid Precursor Protein Proteolysis. J Biol Chem 2016;291:19235-44.

57. Belyaev ND, Kellett KA, Beckett C, et al. The transcriptionally active amyloid precursor protein (APP) intracellular domain is preferentially produced from the 695 isoform of APP in a $\{$ beta $\}$-secretase-dependent pathway. J Biol Chem 2010;285:41443-54.

58. Kimberly WT, Zheng JB, Guénette SY, et al. The intracellular domain of the beta-amyloid precursor protein is stabilized by Fe65 and translocates to the nucleus in a notch-like manner. J Biol Chem 2001;276:40288-92.

59. Cao X, Sudhof TC. A transcriptionally [correction of transcriptively] active complex of APP with Fe65 and histone acetyltransferase Tip60. Science 2001;293:115-20.

60. Kuhn PH, Wang H, Dislich B, et al. ADAM10 is the physiologically relevant, constitutive alpha-secretase of the amyloid precursor protein in primary neurons. EMBO J 2010;29:3020-32.

61. Hardy JA, Higgins GA. Alzheimer's disease: the amyloid cascade hypothesis. Science 1992;256:184-5.

62. Nelson PT, Alafuzoff I, Bigio EH, et al. Correlation of Alzheimer disease neuropathologic changes with cognitive status: a review of the literature. J Neuropathol Exp Neurol 2012;71:362-81.

63. Altmann A, Ng B, Landau SM, et al. Regional brain hypometabolism is unrelated to regional amyloid plaque burden. Brain 2015;138:3734-46.

64. Edison P, Archer HA, Hinz R, et al. Amyloid, hypometabolism, and cognition in Alzheimer disease: an [11C]PIB and [18F]FDG PET study. Neurology 2007;68:501-8.

65. Dixit R, Ross JL, Goldman YE, et al. Differential regulation of dynein and kinesin motor proteins by tau. Science 2008;319:1086-9.

66. Naseri NN, Wang H, Guo J, et al. The complexity of tau in Alzheimer's disease. Neurosci Lett 2019;705:183-94.

67. Iqbal K, Liu F, Gong CX, et al. Tau in Alzheimer disease and related tauopathies. Curr Alzheimer Res 2010;7:656-64.

68. Kou X, Chen D, Chen N. The Regulation of microRNAs in Alzheimer's Disease. Front Neurol 2020;11:288.

69. Gámez-Valero A, Beyer K, Borras FE. Extracellular vesicles, new actors in the search for biomarkers of dementias. Neurobiol Aging 2019;74:15-20.

70. Yagi Y, Ohkubo T, Kawaji H, et al. Next-generation sequencing-based small RNA profiling of cerebrospinal fluid exosomes. Neurosci Lett 2017;636:48-57.

71. Galvanin A, Dostert G, Ayadi L, et al. Diversity and heterogeneity of extracellular RNA in human plasma. Biochimie 2019;164:22-36.

72. Müller M, Jakel L, Bruinsma IB, et al. MicroRNA-29a Is a Candidate Biomarker for Alzheimer's Disease in Cell-Free Cerebrospinal Fluid. Mol Neurobiol 2016;53:2894-9.

73. Lässer C, Shelke GV, Yeri A, et al. Two distinct extracellular RNA signatures released by a single cell type identified by microarray and next-generation sequencing. RNA Biol 2017;14:58-72. 
74. Herrera-Espejo S, Santos-Zorrozua B, Alvarez-Gonzalez P, et al. A Systematic Review of MicroRNA Expression as Biomarker of Late-Onset Alzheimer's Disease. Mol Neurobiol 2019;56:8376-91.

75. Wu HZY, Thalamuthu A, Cheng L, et al. Differential blood miRNA expression in brain amyloid imagingdefined Alzheimer's disease and controls. Alzheimers Res Ther 2020;12:59.

76. Nagaraj S, Zoltowska KM, Laskowska-Kaszub K, et al. microRNA diagnostic panel for Alzheimer's disease and epigenetic trade-off between neurodegeneration and cancer. Ageing Res Rev 2019;49:125-43.

77. Barbagallo C, Mostile G, Baglieri G, et al. Specific Signatures of Serum miRNAs as Potential Biomarkers to Discriminate Clinically Similar Neurodegenerative and Vascular-Related Diseases. Cell Mol Neurobiol 2020;40:531-46.

78. Wu Y, Xu J, Xu J, et al. Lower Serum Levels of miR-29c$3 \mathrm{p}$ and miR-19b-3p as Biomarkers for Alzheimer's Disease. Tohoku J Exp Med 2017;242:129-36.

79. Burgos K, Malenica I, Metpally R, et al. Profiles of extracellular miRNA in cerebrospinal fluid and serum from patients with Alzheimer's and Parkinson's diseases correlate with disease status and features of pathology. PLoS One 2014;9:e94839.

80. Galimberti D, Villa C, Fenoglio C, et al. Circulating miRNAs as potential biomarkers in Alzheimer's disease. $\mathrm{J}$ Alzheimers Dis 2014;42:1261-7.

81. Jia LH, Liu YN. Downregulated serum miR-223 servers as biomarker in Alzheimer's disease. Cell Biochem Funct 2016;34:233-7.

82. Kiko T, Nakagawa K, Tsuduki T, et al. MicroRNAs in plasma and cerebrospinal fluid as potential markers for Alzheimer's disease. J Alzheimers Dis 2014;39:253-9.

83. Lugli G, Cohen AM, Bennett DA, et al. Plasma Exosomal miRNAs in Persons with and without Alzheimer Disease: Altered Expression and Prospects for Biomarkers. PLoS One 2015;10:e0139233.

84. Tan L, Yu JT, Liu QY, et al. Circulating miR-125b as a biomarker of Alzheimer's disease. J Neurol Sci 2014;336:52-6.

85. Villa C, Ridolfi E, Fenoglio C, et al. Expression of the transcription factor Sp1 and its regulatory hsa-miR-29b in peripheral blood mononuclear cells from patients with Alzheimer's disease. J Alzheimers Dis 2013;35:487-94.

86. Geekiyanage H, Jicha GA, Nelson PT, et al. Blood serum miRNA: non-invasive biomarkers for Alzheimer's disease. Exp Neurol 2012;235:491-6.
87. Satoh J, Kino Y, Niida S. MicroRNA-Seq Data Analysis Pipeline to Identify Blood Biomarkers for Alzheimer's Disease from Public Data. Biomark Insights 2015;10:21-31.

88. Yang G, Song Y, Zhou X, et al. MicroRNA-29c targets $\beta$-site amyloid precursor protein-cleaving enzyme 1 and has a neuroprotective role in vitro and in vivo. Mol Med Rep 2015;12:3081-8.

89. Yang G, Song Y, Zhou X, et al. DNA methyltransferase 3 , a target of microRNA-29c, contributes to neuronal proliferation by regulating the expression of brain-derived neurotrophic factor. Mol Med Rep 2015;12:1435-42.

90. Gui Y, Liu H, Zhang L, et al. Altered microRNA profiles in cerebrospinal fluid exosome in Parkinson disease and Alzheimer disease. Oncotarget 2015;6:37043-53.

91. Sørensen SS, Nygaard AB, Christensen T. miRNA expression profiles in cerebrospinal fluid and blood of patients with Alzheimer's disease and other types of dementia - an exploratory study. Transl Neurodegener 2016;5:6.

92. Cheng L, Doecke JD, Sharples RA, et al. Prognostic serum miRNA biomarkers associated with Alzheimer's disease shows concordance with neuropsychological and neuroimaging assessment. Mol Psychiatry 2015;20:1188-96.

93. Tan L, Yu JT, Tan MS, et al. Genome-wide serum microRNA expression profiling identifies serum biomarkers for Alzheimer's disease. J Alzheimers Dis 2014;40:1017-27.

94. Li F, Xie XY, Sui XF, et al. Profile of Pathogenic Proteins and MicroRNAs in Plasma-derived Extracellular Vesicles in Alzheimer's Disease: A Pilot Study. Neuroscience 2020;432:240-6.

95. Görücü Yilmaz Ş, Erdal ME, Avci Özge A, et al. SNP Variation in MicroRNA Biogenesis Pathway Genes as a New Innovation Strategy for Alzheimer Disease Diagnostics: A Study of 10 Candidate Genes in an Understudied Population From the Eastern Mediterranean. Alzheimer Dis Assoc Disord 2016;30:203-9.

96. Wang T, Chen K, Li H, et al. The feasibility of utilizing plasma MiRNA107 and BACE1 messenger RNA gene expression for clinical diagnosis of amnestic mild cognitive impairment. J Clin Psychiatry 2015;76:135-41.

97. Leidinger P, Backes C, Deutscher S, et al. A blood based 12-miRNA signature of Alzheimer disease patients. Genome Biol 2013;14:R78.

98. Wang J, Chen C, Zhang Y. An investigation of microRNA-103 and microRNA-107 as potential bloodbased biomarkers for disease risk and progression of Alzheimer's disease. J Clin Lab Anal 2020;34:e23006. 
99. Cosín-Tomás M, Antonell A, Llado A, et al. Plasma miR-34a-5p and miR-545-3p as Early Biomarkers of Alzheimer's Disease: Potential and Limitations. Mol Neurobiol 2017;54:5550-62.

100.Kumar P, Dezso Z, MacKenzie C, et al. Circulating miRNA biomarkers for Alzheimer's disease. PLoS One 2013;8:e69807.

101. Nagaraj S, Laskowska-Kaszub K, Dębski KJ, et al. Profile of 6 microRNA in blood plasma distinguish early stage Alzheimer's disease patients from non-demented subjects. Oncotarget 2017;8:16122-43.

102.van Harten AC, Mulders J, Scheltens P, et al. Differential Expression of microRNA in Cerebrospinal Fluid as a Potential Novel Biomarker for Alzheimer's Disease. J Alzheimers Dis 2015;47:243-52.

103. Riancho J, Vazquez-Higuera JL, Pozueta A, et al. MicroRNA Profile in Patients with Alzheimer's Disease: Analysis of miR-9-5p and miR-598 in Raw and Exosome Enriched Cerebrospinal Fluid Samples. J Alzheimers Dis 2017;57:483-91.

104. Souza VC, Morais GS Jr, Henriques AD, et al. WholeBlood Levels of MicroRNA-9 Are Decreased in Patients With Late-Onset Alzheimer Disease. Am J Alzheimers Dis Other Demen 2020;35:1533317520911573.

105. Hosaka T, Yamashita T, Tamaoka A, et al. Extracellular RNAs as Biomarkers of Sporadic Amyotrophic Lateral Sclerosis and Other Neurodegenerative Diseases. Int J Mol Sci 2019;20:3148.

106. Kosikova N, Cente M, Cigankova V, et al. miRNAs as biofluid markers for diagnostics of Alzheimer's disease: recent status and perspectives. Gen Physiol Biophys 2018;37:495-514.

107. Kumar S, Reddy PH. Are circulating microRNAs peripheral biomarkers for Alzheimer's disease? Biochim Biophys Acta 2016;1862:1617-27.

108. Saugstad JA, Lusardi TA, Van Keuren-Jensen KR, et al. Analysis of extracellular RNA in cerebrospinal fluid. J Extracell Vesicles 2017;6:1317577.

109.Lusardi TA, Wiedrick JT, Malone M, et al. Analytics of Cerebrospinal Fluid MicroRNA Quantitative PCR Studies. Mol Neurobiol 2019;56:4988-99.

110. Wiedrick JT, Phillips JI, Lusardi TA, et al. Validation of MicroRNA Biomarkers for Alzheimer's Disease in Human Cerebrospinal Fluid. J Alzheimers Dis 2019;67:875-91.

111. Ma P, Li Y, Zhang W, et al. Long Non-coding RNA MALAT1 Inhibits Neuron Apoptosis and Neuroinflammation While Stimulates Neurite Outgrowth and Its Correlation With MiR-125b Mediates PTGS2,
CDK5 and FOXQ1 in Alzheimer's Disease. Curr Alzheimer Res 2019;16:596-612.

112.Jin Y, Tu Q, Liu M. MicroRNA-125b regulates Alzheimer's disease through SphK1 regulation. Mol Med Rep 2018;18:2373-80.

113. Kimura T, Ishiguro K, Hisanaga S. Physiological and pathological phosphorylation of tau by Cdk5. Front Mol Neurosci 2014;7:65.

114. Ma X, Liu L, Meng J. MicroRNA-125b promotes neurons cell apoptosis and Tau phosphorylation in Alzheimer's disease. Neurosci Lett 2017;661:57-62.

115. Banzhaf-Strathmann J, Benito E, May S, et al. MicroRNA$125 \mathrm{~b}$ induces tau hyperphosphorylation and cognitive deficits in Alzheimer's disease. EMBO J 2014;33:1667-80.

116. Tang H, Ma M, Wu Y, et al. Activation of MT2 receptor ameliorates dendritic abnormalities in Alzheimer's disease via $\mathrm{C} / \mathrm{EBP} \alpha / \mathrm{miR}-125 \mathrm{~b}$ pathway. Aging Cell 2019;18:e12902.

117.Lukiw WJ, Pogue AI. Induction of specific micro RNA (miRNA) species by ROS-generating metal sulfates in primary human brain cells. J Inorg Biochem 2007;101:1265-9.

118. Dursun E, Candaş E, Y1lmazer S, et al. Amyloid Beta 1-42 Alters the Expression of miRNAs in Cortical Neurons. J Mol Neurosci 2019;67:181-92.

119. Maldonado-Lasuncion I, Atienza M, Sanchez-Espinosa MP, et al. Aging-Related Changes in Cognition and Cortical Integrity are Associated With Serum Expression of Candidate MicroRNAs for Alzheimer Disease. Cereb Cortex 2019;29:4426-37.

120. Micheli F, Palermo R, Talora C, et al. Regulation of proapoptotic proteins Bak1 and p53 by miR-125b in an experimental model of Alzheimer's disease: Protective role of 17ß-estradiol. Neurosci Lett 2016;629:234-40.

121.Li P, Xu Y, Wang B, et al. miR-34a-5p and miR-125b$5 \mathrm{p}$ attenuate $\mathrm{A} \beta$-induced neurotoxicity through targeting BACE1. J Neurol Sci 2020;413:116793.

122. Pereira PA, Tomás JF, Queiroz JA, et al. Recombinant premiR-29b for Alzheimer's disease therapeutics. Sci Rep 2016;6:19946.

123. Niranjan R. Molecular basis of etiological implications in Alzheimer's disease: focus on neuroinflammation. Mol Neurobiol 2013;48:412-28.

124. Roshan R, Shridhar S, Sarangdhar MA, et al. Brain-specific knockdown of miR-29 results in neuronal cell death and ataxia in mice. Rna 2014;20:1287-97.

125.Zong Y, Yu P, Cheng H, et al. miR-29c regulates NAV3 protein expression in a transgenic mouse model of 
Alzheimer's disease. Brain Res 2015;1624:95-102.

126. Lei X, Lei L, Zhang Z, et al. Downregulated miR-29c correlates with increased BACE1 expression in sporadic Alzheimer's disease. Int J Clin Exp Pathol 2015;8:1565-74.

127.Jahangard Y, Monfared H, Moradi A, et al. Therapeutic Effects of Transplanted Exosomes Containing miR-29b to a Rat Model of Alzheimer's Disease. Front Neurosci 2020;14:564.

128.Fu Y, Hu X, Zheng C, et al. Intrahippocampal miR-342-3p inhibition reduces beta-amyloid plaques and ameliorates learning and memory in Alzheimer's disease. Metab Brain Dis 2019;34:1355-63.

129.Jung YY, Kim KC, Park MH, et al. Atherosclerosis is exacerbated by chitinase-3-like-1 in amyloid precursor protein transgenic mice. Theranostics 2018;8:749-66.

130.Sun X, Wu Y, Gu M, et al. Selective filtering defect at the axon initial segment in Alzheimer's disease mouse models. Proc Natl Acad Sci U S A 2014;111:14271-6.

131.Sun X, Wu Y, Gu M, et al. miR-342-5p decreases ankyrin $\mathrm{G}$ levels in Alzheimer's disease transgenic mouse models. Cell Rep 2014;6:264-70.

132. Finnerty JR, Wang WX, Hébert SS, et al. The miR15/107 group of microRNA genes: evolutionary biology, cellular functions, and roles in human diseases. J Mol Biol 2010;402:491-509.

133.Prendecki M, Florczak-Wyspianska J, Kowalska M, et al. APOE genetic variants and apoE, miR-107 and miR650 levels in Alzheimer's disease. Folia Neuropathol 2019;57:106-16.

134. Chen W, Wu L, Hu Y, et al. MicroRNA-107 Ameliorates Damage in a Cell Model of Alzheimer's Disease by Mediating the FGF7/FGFR2/PI3K/Akt Pathway. J Mol Neurosci 2020;70:1589-97.

135.Li JJ, Dolios G, Wang R, et al. Soluble beta-amyloid peptides, but not insoluble fibrils, have specific effect on neuronal microRNA expression. PLoS One 2014;9:e90770.

136.Xu W, Li K, Fan Q, et al. Knockdown of long noncoding RNA SOX21-AS1 attenuates amyloid- $\beta$-induced neuronal damage by sponging miR-107. Biosci Rep 2020;40:BSR20194295.

137. Ke S, Yang Z, Yang F, et al. Long Noncoding RNA NEAT1 Aggravates A $\beta$-Induced Neuronal Damage by Targeting miR-107 in Alzheimer's Disease. Yonsei Med J 2019;60:640-50.

138. Liu W, Cai H, Lin M, et al. MicroRNA-107 prevents amyloid-beta induced blood-brain barrier disruption and endothelial cell dysfunction by targeting Endophilin-1.
Exp Cell Res 2016;343:248-57.

139.Sun L, Zhang T, Xiu W, et al. MiR-107 overexpression attenuates neurotoxicity induced by 6-hydroxydopamine both in vitro and in vivo. Chem Biol Interact 2020;315:108908.

140.Jiao Y, Kong L, Yao Y, et al. Osthole decreases beta amyloid levels through up-regulation of miR-107 in Alzheimer's disease. Neuropharmacology 2016;108:332-44.

141. Wang WX, Rajeev BW, Stromberg AJ, et al. The expression of microRNA miR-107 decreases early in Alzheimer's disease and may accelerate disease progression through regulation of beta-site amyloid precursor proteincleaving enzyme 1. J Neurosci 2008;28:1213-23.

142. Augustin R, Endres K, Reinhardt S, et al. Computational identification and experimental validation of microRNAs binding to the Alzheimer-related gene ADAM10. BMC Med Genet 2012;13:35.

143.Moncini S, Lunghi M, Valmadre A, et al. The miR-15/107 Family of microRNA Genes Regulates CDK5R1/p35 with Implications for Alzheimer's Disease Pathogenesis. Mol Neurobiol 2017;54:4329-42.

144.Hu W, Wen L, Cao F, et al. Down-Regulation of Mir-107 Worsen Spatial Memory by Suppressing SYK Expression and Inactivating NF-KB Signaling Pathway. Curr Alzheimer Res 2019;16:135-45.

145. Yao J, Hennessey T, Flynt A, et al. MicroRNA-related cofilin abnormality in Alzheimer's disease. PloS one 2010;5:e15546.

146. Shu B, Zhang X, Du G, et al. MicroRNA-107 prevents amyloid- $\beta$-induced neurotoxicity and memory impairment in mice. Int J Mol Med 2018;41:1665-72.

147. Gong G, An F, Wang Y, et al. miR-15b represses BACE1 expression in sporadic Alzheimer's disease. Oncotarget 2017;8:91551-7.

148. Li J, Wang H. miR-15b reduces amyloid- $\beta$ accumulation in SH-SY5Y cell line through targetting NF- $\mathrm{BB}$ signaling and BACE1. Biosci Rep 2018;38:BSR20180051.

149. Liu HY, Fu X, Li YF, et al. miR-15b-5p targeting amyloid precursor protein is involved in the anti-amyloid eflect of curcumin in swAPP695-HEK293 cells. Neural Regen Res 2019;14:1603-9.

150.Song J, Kim YK. Identification of the Role of miR-142-5p in Alzheimer's Disease by Comparative Bioinformatics and Cellular Analysis. Front Mol Neurosci 2017;10:227.

151.Xu H, Yue C, Chen L. Post-Transcriptional Regulation of Soluble Guanylate Cyclase that Governs Neuropathic Pain in Alzheimer's Disease. J Alzheimers Dis 2019;71:1331-8. 152.Zhang N, Gao Y, Yu S, et al. Berberine attenuates A $\beta 42-$ 
induced neuronal damage through regulating circHDAC9/ miR-142-5p axis in human neuronal cells. Life Sci 2020;252:117637.

153. Ghanbari M, Munshi ST, Ma B, et al. A functional variant in the miR-142 promoter modulating its expression and conferring risk of Alzheimer disease. Hum Mutat 2019;40:2131-45.

154. Rahaie M, Noroozi SK. A nanobiosensor based on graphene oxide and DNA binding dye for multimicroRNAs detection. Biosci Rep 2019;39:BSR20181404.

155.Liu B, Cao W, Xue J. LncRNA ANRIL protects against oxygen and glucose deprivation (OGD)-induced injury in PC-12 cells: potential role in ischaemic stroke. Artif Cells Nanomed Biotechnol 2019;47:1384-95.

156.He QQ, Xiong LL, Liu F, et al. MicroRNA-127 targeting of mitoNEET inhibits neurite outgrowth, induces cell apoptosis and contributes to physiological dysfunction after spinal cord transection. Sci Rep 2016;6:35205.

157. Tang Y, Bao JS, Su JH, et al. MicroRNA-139 modulates Alzheimer's-associated pathogenesis in SAMP8 mice by targeting cannabinoid receptor type 2. Genet Mol Res 2017. doi: 10.4238/gmr16019166.

158. Wu W, Zheng T, Tian Y. An enzyme-free amplification strategy based on two-photon fluorescent carbon dots for monitoring miR-9 in live neurons and brain tissues of Alzheimer's disease mice. Chem Commun (Camb) 2020;56:8083-6.

159. Wei N, Zheng K, Xue R, et al. Suppression of microRNA$9-5 \mathrm{p}$ rescues learning and memory in chronic cerebral hypoperfusion rats model. Oncotarget 2017;8:107920-31.

160.Li F, Chen A, Zhang J. miR-9 stimulation enhances the differentiation of neural stem cells with zoanthamine by regulating Notch signaling. Am J Transl Res 2019;11:1780-8.

161.Li SH, Gao P, Wang LT, et al. Osthole Stimulated Neural Stem Cells Differentiation into Neurons in an Alzheimer's Disease Cell Model via Upregulation of MicroRNA-9 and Rescued the Functional Impairment of Hippocampal Neurons in APP/PS1 Transgenic Mice. Front Neurosci 2017;11:340.

162.Li S, Yan Y, Jiao Y, et al. Neuroprotective Effect of Osthole on Neuron Synapses in an Alzheimer's Disease Cell Model via Upregulation of MicroRNA-9. J Mol Neurosci 2016;60:71-81.

163. Chang F, Zhang LH, Xu WP, et al. microRNA-9 attenuates amyloid $\beta$-induced synaptotoxicity by targeting calcium/calmodulin-dependent protein kinase kinase 2 . Mol Med Rep 2014;9:1917-22.
164. Schonrock N, Humphreys DT, Preiss T, et al. Target gene repression mediated by miRNAs miR-181c and miR-9 both of which are down-regulated by amyloid- $\beta$. J Mol Neurosci 2012;46:324-35.

165. Wu X, Pan Y, Fang Y, et al. The Biogenesis and Functions of piRNAs in Human Diseases. Mol Ther Nucleic Acids 2020;21:108-20.

166. Roy J, Sarkar A, Parida S, et al. Small RNA sequencing revealed dysregulated piRNAs in Alzheimer's disease and their probable role in pathogenesis. Mol Biosyst 2017;13:565-76.

167. Roy J, Anand K, Mohapatra S, et al. Single nucleotide polymorphisms in piRNA-pathway genes: an insight into genetic determinants of human diseases. Mol Genet Genomics 2020;295:1-12.

168. Jain G, Stuendl A, Rao P, et al. A combined miRNApiRNA signature to detect Alzheimer's disease. Transl Psychiatry 2019;9:250.

169.Li D, Zhang J, Li X, et al. Insights into lncRNAs in Alzheimer's Disease Mechanisms. RNA Biol 2020. [Epub ahead of print]. doi: 10.1080/15476286.2020.1788848.

170.Zhao Y, Zhang Y, Zhang L, et al. The Potential Markers of Circulating microRNAs and long non-coding RNAs in Alzheimer's Disease. Aging Dis 2019;10:1293-301.

171. Feng L, Liao YT, He JC, et al. Plasma long non-coding RNA BACE1 as a novel biomarker for diagnosis of Alzheimer disease. BMC Neurol 2018;18:4.

172. Fotuhi SN, Khalaj-Kondori M, Hoseinpour Feizi MA, et al. Long Non-coding RNA BACE1-AS May Serve as an Alzheimer's Disease Blood-Based Biomarker. J Mol Neurosci 2019;69:351-9.

173.Zhang W, Zhao H, Wu Q, et al. Knockdown of BACE1AS by siRNA improves memory and learning behaviors in Alzheimer's disease animal model. Exp Ther Med 2018;16:2080-6.

174.Li F, Wang Y, Yang H, et al. The effect of BACE1-AS on $\beta$-amyloid generation by regulating BACE1 mRNA expression. BMC Mol Biol 2019;20:23.

175. Ebermann C, Schnarr T, Müller S. Recent advances in understanding circular RNAs. F1000Res 2020;9:F1000 Faculty Rev-655.

176. Li Y, Lv Z, Zhang J, et al. Profiling of differentially expressed circular RNAs in peripheral blood mononuclear cells from Alzheimer's disease patients. Metab Brain Dis 2020;35:201-13.

177.Lu Y, Tan L, Wang X. Circular HDAC9/microRNA-138/ Sirtuin-1 Pathway Mediates Synaptic and Amyloid Precursor Protein Processing Deficits in Alzheimer's 
Disease. Neurosci Bull 2019;35:877-88.

178. Imenshahidi M, Hosseinzadeh H. Berberis Vulgaris and Berberine: An Update Review. Phytother Res 2016;30:1745-64.

179. Fan D, Liu L, Wu Z, et al. Combating Neurodegenerative Diseases with the Plant Alkaloid Berberine: Molecular Mechanisms and Therapeutic Potential. Curr Neuropharmacol 2019;17:563-79.

180. Yan Z, Zhou Z, Wu Q, et al. Presymptomatic Increase of an Extracellular RNA in Blood Plasma Associates with the Development of Alzheimer's Disease. Curr Biol 2020;30:1771-1782.e3.

181. Mitsuhashi M, Taub DD, Kapogiannis D, et al. Aging enhances release of exosomal cytokine mRNAs by Abeta142-stimulated macrophages. Faseb J 2013;27:5141-50.

182.Lukiw WJ, Bazan NG. Cyclooxygenase 2 RNA message abundance, stability, and hypervariability in sporadic Alzheimer neocortex. J Neurosci Res 1997;50:937-45.

183. Barbash S, Garfinkel BP, Maoz R, et al. Alzheimer's brains show inter-related changes in RNA and lipid metabolism. Neurobiol Dis 2017;106:1-13.

184. Patel R, Brophy C, Hickling M, et al. Alternative cleavage and polyadenylation of genes associated with protein turnover and mitochondrial function are deregulated in Parkinson's, Alzheimer's and ALS disease. BMC Med Genomics 2019;12:60.

185.Zheng D, Wang R, Ding Q, et al. Cellular stress alters 3'UTR landscape through alternative polyadenylation and isoform-specific degradation. Nat Commun 2018;9:2268.

186. Colombrita C, Zennaro E, Fallini C, et al. TDP-43 is recruited to stress granules in conditions of oxidative insult. J Neurochem 2009;111:1051-61.

187. Chendrimada TP, Gregory RI, Kumaraswamy E, et al. TRBP recruits the Dicer complex to Ago2 for microRNA processing and gene silencing. Nature 2005;436:740-4.

188. Amador-Ortiz C, Lin WL, Ahmed Z, et al. TDP-43 immunoreactivity in hippocampal sclerosis and Alzheimer's disease. Ann Neurol 2007;61:435-45.

189. Collins M, Li Y, Bowser R. RBM45 associates with nuclear stress bodies and forms nuclear inclusions during chronic cellular stress and in neurodegenerative diseases. Acta Neuropathol Commun 2020;8:91.

190. Hicks DA, Cross LL, Williamson R, et al. Endoplasmic Reticulum Stress Signalling Induces Casein Kinase 1-Dependent Formation of Cytosolic TDP-43 Inclusions in Motor Neuron-Like Cells. Neurochem Res 2020;45:1354-64.

191. Yamoah A, Tripathi P, Sechi A, et al. Aggregates of RNA
Binding Proteins and ER Chaperones Linked to Exosomes in Granulovacuolar Degeneration of the Alzheimer's Disease Brain. J Alzheimers Dis 2020;75:139-56.

192. Kajiwara Y, Wang E, Wang M, et al. GJA1 (connexin43) is a key regulator of Alzheimer's disease pathogenesis. Acta Neuropathol Commun 2018;6:144.

193. Geuens T, Bouhy D, Timmerman V. The hnRNP family: insights into their role in health and disease. Hum Genet 2016;135:851-67.

194. Sackmann C, Hallbeck M. Oligomeric amyloid- $\beta$ induces early and widespread changes to the proteome in human iPSC-derived neurons. Sci Rep 2020;10:6538.

195. Mordovkina D, Lyabin DN, Smolin EA, et al. Y-Box Binding Proteins in mRNP Assembly, Translation, and Stability Control. Biomolecules 2020;10:591.

196. Berson A, Barbash S, Shaltiel G, et al. Cholinergicassociated loss of hnRNP-A/B in Alzheimer's disease impairs cortical splicing and cognitive function in mice. EMBO Mol Med 2012;4:730-42.

197. Chevillet JR, Kang Q, Ruf IK, et al. Quantitative and stoichiometric analysis of the microRNA content of exosomes. Proc Natl Acad Sci U S A 2014;111:14888-93.

198. He D, Wang H, Ho SL, et al. Total internal reflectionbased single-vesicle in situ quantitative and stoichiometric analysis of tumor-derived exosomal microRNAs for diagnosis and treatment monitoring. Theranostics 2019;9:4494-507.

199. Stevanato L, Thanabalasundaram L, Vysokov N, et al. Investigation of Content, Stoichiometry and Transfer of miRNA from Human Neural Stem Cell Line Derived Exosomes. PLoS One 2016;11:e0146353.

200. Koritzinsky EH, Street JM, Star RA, et al. Quantification of Exosomes. J Cell Physiol 2017;232:1587-90.

201. Davidson SM, Riquelme JA, Zheng Y, et al. Endothelial cells release cardioprotective exosomes that may contribute to ischaemic preconditioning. Sci Rep 2018;8:15885.

202.Lefebvre FA, Lécuyer E. Small Luggage for a Long Journey: Transfer of Vesicle-Enclosed Small RNA in Interspecies Communication. Front Microbiol 2017;8:377.

203. Swarbrick S, Wragg N, Ghosh S, et al. Systematic Review of miRNA as Biomarkers in Alzheimer's Disease. Mol Neurobiol 2019;56:6156-67.

204. Murillo OD, Thistlethwaite W, Rozowsky J, et al. exRNA Atlas Analysis Reveals Distinct Extracellular RNA Cargo Types and Their Carriers Present across Human Biofluids. Cell 2019;177:463-477.e15.

205.Atri A. The Alzheimer's Disease Clinical Spectrum: Diagnosis and Management. Med Clin North Am 
2019;103:263-93.

206. Bertram L, Tanzi RE. Thirty years of Alzheimer's disease genetics: the implications of systematic meta-analyses. Nat Rev Neurosci 2008;9:768-78.

207. Tian Y, Gong M, Hu Y, et al. Quality and efficiency assessment of six extracellular vesicle isolation methods by nano-flow cytometry. J Extracell Vesicles 2019;9:1697028.

208. Corso G, Heusermann W, Trojer D, et al. Systematic characterization of extracellular vesicle sorting domains and quantification at the single molecule - single vesicle level by fluorescence correlation spectroscopy and single particle imaging. J Extracell Vesicles 2019;8:1663043.

209. Fraser K, Jo A, Giedt J, et al. Characterization of single microvesicles in plasma from glioblastoma patients. Neuro Oncol 2019;21:606-15.

doi: $10.21037 /$ exrna-21-2

Cite this article as: Hicks DA. Extracellular RNA in Alzheimer's disease. ExRNA 2021;3:1.
210. Lee K, Fraser K, Ghaddar B, et al. Multiplexed Profiling of Single Extracellular Vesicles. ACS Nano 2018;12:494-503.

211. Görgens A, Bremer M, Ferrer-Tur R, et al. Optimisation of imaging flow cytometry for the analysis of single extracellular vesicles by using fluorescence-tagged vesicles as biological reference material. J Extracell Vesicles 2019;8:1587567.

212. Nolan JP, Duggan E. Analysis of Individual Extracellular Vesicles by Flow Cytometry. Methods Mol Biol 2018;1678:79-92.

213. Gupta RK, Kuznicki J. Biological and Medical Importance of Cellular Heterogeneity Deciphered by Single-Cell RNA Sequencing. Cells 2020;9:1751.

214.Labib M, Kelley SO. Single-cell analysis targeting the proteome. Nature Reviews Chemistry 2020;4:143-58. 